\section{Ensino e formação: a prática apaixonada de uma semioticista*}

Teaching and education: the passionate practice of $a$ semiotician

Eliane Soares de LIMA (USP) li.soli@usp.br

Recebido em: 17 de dez. de 2019. Aceito em: 05 de fev. de 2019.

*Texto da conferência apresentada no IV Colóquio Cearense de Semiótica em homenagem a Diana Luz Pessoa de Barros, que aconteceu nos dias 3 e 4 de junho de 2019, na Universidade Federal do Ceará (UFC), Fortaleza.
LIMA, Eliane Soares de. Ensino e formação: a prática apaixonada de uma semioticista. Entrepalavras, Fortaleza, v. 10, n. esp., p. 87-101, mai. 2020. DOI: 10.22168/2237-63217esp1798

Resumo: O texto apresentado tem a intenção de fazer um breve registro de alguns pontos do percurso profissional exemplar - porque verdadeiramente empenhado no compromisso com $\mathrm{O}$ ensino e a formação de seus alunos no contexto da Academia - da professora Diana Luz Pessoa de Barros. Sem qualquer pretensão de contribuição científica, o objetivo é unicamente o de prestar uma justa homenagem a ela, o que explica, e justifica, a adoção de um tom bastante pessoal e exacerbadamente afetivo, típico aos discursos da admiração. De toda forma, na tentativa de apresentar um "estilo Diana de ser professora" um pouco mais objetivo, propõe-se também uma breve análise de relatos recolhidos entre seus ex-alunos e orientandos.

Palavras-chave: Homenagem. Diana Luz Pessoa de Barros. Ensino. 


\section{v. 10 (esp.}

87-101 mai.

2020

Abstract: This text aims at making a brief record of some points of the exemplary professional journey - so deeply committed to the teaching and formation of her students in the University - of professor Diana Luz Pessoa de Barros. Without making any scientific claims, our presentation would simply like to pay tribute to her lifetime carreer, which explains the adoption of a very personal and affective tone, typical of the discourses of admiration. In any case, in an attempt to make this "Diana Luz style of being a teacher" a little more objective, we also propose a brief analysis of some testimonials collected among her former students.

Keywords: Tribute. Diana Luz Pessoa de Barros. Teaching.

Permeando a intenção de registro de um percurso profissional exemplar - porque verdadeiramente empenhado no compromisso de ensino e formação no contexto da Academia - com os afetos a partir daí despertados, este texto, para além de qualquer pretensão de contribuição científica, quer apenas prestar uma justa homenagem, o que explica a adoção de um tom bastante pessoal e exacerbadamente afetivo.

Antes de mais nada, quero agradecer aos organizadores deste número da Entrepalavras, os professores José Américo Saraiva, Ricardo Leite e Carolina Lindemberg Lemos, também responsáveis pelo IV Colóquio Cearense de Semiótica, que homenageou a professora Diana Luz Pessoa de Barros, nos dias 3 e 4 de junho de 2019, pela oportunidade de poder manifestar publicamente a minha imensa admiração tanto pelo trabalho desenvolvido por ela ao longo de sua carreira como docente, pesquisadora e orientadora - entre tantas outras funções acadêmicas que não se absteve de assumir quando se mostrava necessário -, quanto pela sua conduta pessoal.

Em tempos sombrios como o que estamos vivendo, no qual um governo declara guerra à Educação Pública, empenhando-se em desmoralizar as Universidades e mesmo a figura do professor, um evento como o que foi realizado, seguido desta publicação, apresentase, sem dúvida, como ato de resistência, mostrando que os professores - sobretudo, os de excelência, como é o caso aqui - merecem apenas homenagens, com todo louvor e a distinção que ao seu trabalho cabem; mostrando ainda que o percurso profissional de uma professora como a Diana não deixa dúvidas quanto à importância e à contribuição da Universidade à sociedade.

Devo confessar que esta oportunidade éainda muito importante para mim, porque me dá a chance - desta vez, sem espaço para desistência - de transformar um estado de falta. Explico: na ocasião 
da homenagem feita aos professores de semiótica aposentados da USP, em maio de 2017, "O percurso da semiótica na USP: uma homenagem a Diana Luz Pessoa de Barros, José Luiz Fiorin, Beth Brait, Luiz Tatit e Norma Discini", tínhamos a possibilidade de deixar uma mensagem para os homenageados, relatando algum momento especial, um agradecimento, a admiração, ou o que quer que fosse para homenageálos. Escrevi para todos, menos para Diana. Não por falta de admiração, mas por excesso. Pensei, repensei. Ensaiei algumas frases, mas nada parecia dar conta do sentimento que ela desperta. Embora, de minha parte, um contato mais próximo com a Diana seja recente, comparado com a convivência de anos e anos de alguns, eu simplesmente não fui capaz de encontrar um equilíbrio entre o sensível e o inteligível para manifestar o meu agradecimento ao que ela representa para todos nós, de modo que acabei desistindo de tentar. Talvez, porque, como explica Thürlemann, em um estudo seu sobre o efeito passional da admiração, publicado em um dos números dos Documents de 1980 (n. 11):

A conjunção com o objeto 'raro e extraordinário' não resulta imediatamente na aquisição de um saber. Por sua natureza complexa, o objeto 'resiste' de alguma forma à conjunção com o sujeito do conhecimento. E é precisamente essa 'resistência' que provoca a 'admiração'. (THÜRLEMANN, 1980, p. 23, tradução nossa' ${ }^{1}$

Ainda que a admiração seja, de fato, um estado patêmico complexo - como também a define Elizabeth Rallo Ditche, no Dictionnaire des passions littéraires (2005), salientando, como Thürlemann, o impacto sobre a capacidade de julgamento que ela promove, carreguei essa falta, porque antes ser sentimental, do que nada dizer.

Acho que todos os que conhecem a Diana podem me compreender. Falar dela, que tanta admiração desperta, sem ser um pouco piegas, não é tarefa simples, justamente porque, inevitavelmente, envolve muitas paixões, uma interpretação judicativa sobredeterminada por afetos, como irão comprovar as vozes que trago aqui em meu texto. Não é preciso muito tempo de convivência para ser impactado por sua presença viva, contagiante e sempre inspiradora.

Enfim, sem poder desistir desta vez - e muito feliz por isso, uma vez que o dever imposto é na verdade um querer intenso

\footnotetext{
1 "La conjonction avec l'objet 'rare et extradinaire' n'aboutit pas immédiatement à l'acquisition d'un savoir. Par sa nature complexe, l'objet 'résiste' en quelque sorte à la conjonction avec le sujet connaissant. Et c'est justement cette 'résistance' qui provoque l'admiration".
} 


\section{v. 10 (esp.}

87-101 mai. 2020
- fui então procurar um caminho para, finalmente, encarar o desafio de equilibrar o sensível e o inteligível na minha apreensão da Diana professora e orientadora, e que não deixa de demonstrar muito do que ela é como pessoa, ou como "sujeito no mundo", diria Norma Discini.

Encontrei uma forma por meio daquilo que - acho eu mais sei fazer, graças à semiótica e aos professores que, como a Diana, me capacitaram para isso: analisar textos. Afinal, como nos ensina a teoria, não há nada mais apropriado para depreender a imagem de um ator da enunciação, do que os textos que ele produz. Trata-se, retomando novamente as palavras de Discini (2018, p. 118), de "interrogar o sujeito discursivo como um ator da enunciação e como estilo". Textos que comprovam que a Diana, sim, sempre soube encontrar equilíbrio entre o inteligível e o sensível, entre o rigor, exigido pelo trabalho científico, e a humanidade, necessária à interação com o outro - e essa é uma de suas características mais marcantes, um dos motivos pelos quais, parece-me, ela acumula tantos admiradores, como eu.

Os discursos que recolhi ganham, todavia, ainda mais sentido quando articulados ao percurso narrativo da Diana professora, sobre o qual passo a me deter agora.

\section{Uma trajetória profissional exemplar}

Diana Luz Pessoa de Barros inicia sua carreira docente em 1973, como professora auxiliar no Departamento de Linguística e Línguas Orientais na Faculdade de Filosofia, Letras e Ciências Humanas da Universidade de São Paulo. Na verdade, antes disso, já havia atuado, em 1969, como monitora na disciplina de Teoria da Literatura, na Faculdade de Filosofia, Ciências e Letras de São José do Rio Preto hoje um dos câmpus da UNESP. Em 1971, logo após o seu mestrado na França, com Greimas, também havia sido monitora na disciplina de Literatura Brasileira.

De 1972 a 1974, foi professora auxiliar, passando, de 1974 a 1976, a professora assistente, na área de Linguística, da Faculdade de Filosofia, Ciências e Letras de São José do Rio Preto. Foi lá que, conforme suas próprias palavras, aprendeu, com "Eduardo Peñuela Cañizal, Ignacio Assis Silva e Alceu Dias Lima, em aulas de literatura, linguística e latim, o que significa ser professor universitário no Brasil" (BARROS, 2017b, p. 3). 
Com pendor ao trabalho árduo, como já mostra a atuação simultânea nas duas universidades citadas, e o compromisso com o ensino e a formação numa área que ainda lutava para se estabelecer e demonstrar o seu valor entre os estudos científicos, como era o caso da Linguística no Brasil, e mais ainda o da Semiótica, Diana não limitou sua ação docente aos cursos de Letras das duas universidades. De 1977, um ano após a defesa de seu Doutorado, a 1985, ministrou a disciplina "Sistemas sígnicos não-verbais" na Graduação em Jornalismo na ECA - Escola de Comunicações e Artes da Universidade de São Paulo; e, de 1978 a 1980, após um segundo estágio na França, quando teve a oportunidade de participar do grupo de trabalho dirigido por Jean-Marie Floch, ministrou também a disciplina "Semiótica Visual" no Programa de Pós-graduação da ECA.

Não foi só isso. De 1978 a 1981, atuou como professora colaboradora (celetista) na Faculdade de Filosofia, Ciências e Letras Barão de Mauá, em Ribeirão Preto, interior de São Paulo², onde ministrou, no Programa de Pós-Graduação em Letras, as disciplinas: Análise da Narrativa e do Discurso; Sistemas sígnicos não-verbais; e Semântica.

Docência e pesquisa, ainda que o regime de trabalho de dedicação exclusiva tenha vindo apenas em 1983, 10 anos após a sua contratação na USP, mantiveram contínuo diálogo em seu percurso. Ao mesmo tempo em que formava pessoas, ou exatamente por isso, nunca deixou de estudar para aprimorar e enriquecer seus conhecimentos sobre o uso da língua, da linguagem, do discurso e sua significação, nas diversas vertentes dos estudos linguísticos, mas sempre apresentando como sua a perspectiva da Semiótica de Greimas.

Em todos esses anos de carreira, de 1972 até hoje, Diana tem difundido o conhecimento adquirido por meio das pesquisas desenvolvidas, do debate com os colegas de área. São quase 400 participações em eventos científicos, seja como conferencista, palestrante, ou com uma simples apresentação de trabalho, para não falar dos cursos e minicursos dados e das centenas de publicações em livros, capítulos e artigos em periódicos científicos. Impressionante nos números e também na qualidade, a produção científica de Diana desperta

\footnotetext{
${ }^{2}$ O Centro Universitário Barão de Mauá, de Ribeirão Preto, SP, ganhou um lugar na história da semiótica local por ter sediado o primeiro curso ministrado em terras brasileiras por Greimas, em julho de 1973, sobre narratividade, a convite do professor Edward Lopes. Diana, que lá estava, conta (BARROS, 2017a) da satisfação de Greimas ao vê-la entre os participantes. Na mesma ocasião, ali foram fundados o Centro de Estudos Semióticos Algirdas Julien Greimas e a revista Significação, que durante mais de três décadas ostentou o título de "Revista Brasileira de Semiótica".
} 


\section{v. 10 (esp.}

87-101 mai. 2020

ainda maior admiração quando percebemos, na convivência, o quanto ela imprime de alegria no que faz ${ }^{3}$ - e esta é outra das características marcantes da Diana.

Os frutos de seu trabalho como professora e pesquisadora, exercido sempre com grande dedicação e competência, foram logo percebidos por outras instituições, no Brasil e no Exterior, nas quais atuou como professora visitante: a Universidade Federal de Minas Gerais (UFMG), onde, em 1986 - um ano após a defesa de sua livredocência - ministrou a disciplina "Texto e meta-texto"; a UNESP, em 1987, com a disciplina "Fundamentos de uma linguística do texto"; a Universidad de Los Andes, na Venezuela, primeiro em 1991, com a disciplina "Desenvolvimentos atuais dos estudos do texto e do discurso", depois, em 2004, com a disciplina "Discurso e ensino"; e na Université de Limoges, na França, em 2006, com a disciplina "Epistémologie et modèles en linguistique et sémiotique [Epistemologia e modelos linguísticos e semióticos]".

Difundindo o saber, e em especial a proposta teóricometodológica da semiótica greimasiana, por onde passa, Diana lecionou na Faculdade de Filosofia, Letras e Ciências Humanas da Universidade de São Paulo até 2002. Nesses 30 anos de trabalho na USP, que tiveram continuidade por meio de sua atuação, ainda hoje, no Programa de Pós-Graduação em Linguística, foi no ensino, na formação de bons pesquisadores, de bons semioticistas, que ela perenizou o seu legado isso, para além da importância de seu papel institucional, reconhecido pela própria Faculdade de Filosofia, Letras e Ciências Humanas da Universidade de São Paulo, ao lhe outorgar, em 2017, o título de Professora Emérita.

Modelo impecável de professora, pesquisadora e orientadora, Diana é inspiração para todos, desde seus primeiros alunos e orientandos, até aqueles que, hoje, de uma forma ou outra, beneficiam-se dos resultados de seu compromisso apaixonado com o ensino, a pesquisa e com a "causa semiótica", para a qual tem contribuído incansavelmente desde os seus primeiros contatos com Greimas nos anos 1970. Ela mesma declarou, na ocasião da homenagem ao percurso da semiótica na USP, que a tarefa de formar os alunos, na graduação e na pós, foi sempre a que exerceu com maior prazer e entusiasmo (BARROS, 2017b).

\footnotetext{
${ }^{3}$ Como um bom exemplo da conhecida expressão de Montaigne, "Je ne fais rien sans gaieté". No Brasil, a sentença ganhou notoriedade especialmente a partir de sua adoção, como lema, por José Mindlin, que a registrava em todos os livros de sua rica biblioteca.
} 
São, de fato, numerosos os alunos formados por ela; muitos deles já professores de longa data em outras universidades públicas.

Dos mais de 50 trabalhos que orientou até o momento (entre mestrados e doutorados, resultantes de sua atuação como orientadora na USP e, na sequência, também no Mackenzie), cinco foram premiados (em 1998, 2002, 2006, 2011 e 2012), comprovando a excelência de seu papel de formadora, que se mostra também, é preciso dizer, em suas intervenções como avaliadora de trabalhos. São mais de 100 participações em bancas examinadoras de qualificação e defesa de Teses e Dissertações dos mais variados temas, e em todas elas - como tive o prazer de testemunhar em algumas ocasiões - suas arguições são sempre uma aula, uma orientação completa, com apontamentos precisos, pertinentes e inspiradores.

Professora de vocação evidente - talvez porque nascida em casa de professores, de quem terá aprendido o compromisso com o ensino, o empenho com a formação inicial de seus alunos -, Diana encantou e encanta a todos aqueles que já tiveram a oportunidade de ter aulas com ela; e, para comprovar isso, passo agora à apresentação do meu corpus.

\section{Discursos da admiração}

Como eu havia mencionado no início deste texto de homenagem, o corpus de análise para depreensão do estilo Diana de ser professora/ orientadora foi composto por textos inspirados por sua prática didática. Na tentativa de "driblar", um pouco, o meu olhar apaixonado, porque tomado de admiração, uma boa saída foi recorrer à impressão de outros para construir uma imagem mais objetiva da Diana professora e orientadora, recolhendo de alguns informantes, ex-alunos e/ou ex-orientandos dela, o depoimento sobre suas aulas e os momentos de orientação. A pergunta de base foi: "Como era a Diana professora?", acrescentando para alguns a pergunta "E como orientadora?" - isso para aqueles que tinham sido seus alunos há mais tempo; para os que tiveram esse contato mais recentemente, usei o verbo ser no presente: "Como é a Diana professora? Orientadora?". Passo, então, à apresentação de alguns dos depoimentos recebidos:

Para mim, a principal característica da Diana é a atitude afetuosa, até maternal que ela imprime em tudo o que faz. Essa atitude transparecia nas aulas de semiótica na FFLCH, quando ela decifrava as mais complicadas teorias com a ajuda de 


\section{10 (esp.)}

87-101 mai. 2020

exemplos extraídos de vivências familiares, bem próximas do cotidiano dos alunos. Manifestava-se também em sua atuação como orientadora de pesquisas, pela abertura ao diálogo, a disponibilidade em receber orientandos sempre cheios de dúvidas e carentes de atenção, na postura segura e confiante que transmitia aos alunos nesses momentos delicados de suas trajetórias acadêmicas, e também na exigência de responsabilidade e seriedade dos discípulos ao longo de todo o ciclo de suas pesquisas. O traço afetivo ainda está presente nos relacionamentos pessoais que a Diana constrói com colegas e alunos: muitos passam a conviver com sua família e ganham acesso à sua própria casa, que se tornou o centro de famosas reuniões, de trabalho ou de congraçamento. É assim que a Diana, com cuidado e carinho, mas também com firmeza, encanta os alunos, engaja-os na causa da semiótica, apresenta-os aos círculos acadêmicos e lhes aponta os primeiros caminhos de atuação. (Paulo Eduardo Lopes)

Diana foi minha professora no meu primeiro semestre de doutorado, isso foi em 1990. Eu nunca tinha estudado semiótica e aparece aquela professora cheia de método, certeza e sabedoria. Foi um presente! Muito didática, sempre preocupada com a compreensão dos alunos, ótima em exemplos (que não trazia prontos, mas parecia inventar na hora, tomar uma situação, um acontecimento do momento e aproveitá-lo). Não tratava a semiótica como modelo, muito menos como paixão ou como o milagre capaz de resolver tudo em interpretação de textos. Tratava como deve ser tratada: como ciência, dotada de rigor e método, propostas consistentes e fundamentação teórica bem articulada e madura. Falava de Greimas com a intimidade de quem conheceu o mestre, mas sem deslumbramento. Citava os semioticistas que líamos e haviam sido seus colegas, como Floch e Fontanille, sem fazer disso motivo de particular presunção. Diana sempre foi simples, objetiva, moderna e racional. Mas também delicada, gentil, interessada e profundamente dedicada ao ensino, à semiótica e à universidade. (Lucia Teixeira)

As aulas da Diana eram muito boas. Lá nas salas das colmeias da USP. Uma sala apertada, lotada de gente. Ela chegava, sentava e começava a falar. [Preciso dizer que, neste momento do relato, interrompi para perguntar: "e não eram chatas as aulas com uma professora que chegava, sentava e falava sem parar?" E o informante, sem qualquer hesitação, com um sorriso, explicou...] Não. É a Diana. Ela falava com entusiasmo e com a naturalidade de quem conhece a fundo o seu território. Distribuía o olhar a todos, sempre sorrindo e dando muitos exemplos com base em situações cotidianas, da vida em casa, nos espaços da cidade. Sempre remetia ao contexto sóciohistórico, político, num discurso engajado e ao mesmo tempo alegre. A Diana era e é um dínamo, uma força irresistível. Saíamos todos embevecidos, empolgados, porque as aulas eram muito inspiradoras. (Ivã Carlos Lopes)

A Diana professora é muito organizada na exposição de suas aulas, sempre teve um discurso muito didático e claro para ensinar a semiótica. Além disso, tem uma capacidade de síntese invejável. Já participei de vários debates em que ela organiza a 
fala de todos e chega a conclusões. Como orientadora, é bastante exigente com seus orientandos, mas sempre uma pessoa aberta a ouvir e a discutir as propostas deles, aceitando-as quando reconhece mérito ou recusando-as com argumentação e explicação. (Arnaldo Cortina)

Diana é acolhedora e tem um olhar muito abrangente sobre o trabalho que orienta, ela vê o lado acadêmico mas também enxerga o lado humano, o que é uma combinação maravilhosa, porque faz dela mestre em muitos aspectos. (Ana Carolina Cortez Noronha)

Realizei o bacharelado em Linguística, na FFLCH, em 2004, e desde aquela época eu já escutava que a Diana era a "mãe dos semioticistas" e isso constatei de perto, no período do mestrado, anos depois. Fui seu aluno e orientando e esse encontro resultou em muito aprendizado. Os debates sobre temas atuais passavam por suas aulas, assim como as análises semióticas com exemplos de intolerância na sociedade, literatura, anúncios publicitários e permaneciam em minha forma de conduzir a pesquisa e a academia. Diana como orientadora tem olhar atento a cada vírgula, ponto, a cada período mal escrito, aos sentidos produzidos. Cuidadosa e sincera em todo o processo. Confesso que guardo com carinho as anotações realizadas por ela (e foram muitas!), assim como as trocas de e-mail (anotações em amarelo e em vermelho) apresentando o que estava bom e o que não estava, o que deveria ser cortado e o que deveria ser adicionado. Guardo também até um teste de canetinhas coloridas no verso de uma das folhas do rascunho da dissertação, que depois Diana docemente revelara ter sido feito por ela para mostrar as cores das canetinhas para a sua neta. Diana, mãe da semiótica, aquela professora que tem gosto por ensinar, por dar exemplos com base em narrativas francesas e brasileiras e que tem muita coragem para debater os temas atuais de nosso país. Posso dizer que tive a felicidade de ter sido orientando da professora Diana e agradeço, como já fiz por diversas vezes, por ela estar em minha trajetória acadêmica, por ter aberto perspectivas em minha vida e por seu papel em meu retorno à semiótica e à linguística. Diana calmaria, Diana mar revolto, Diana coerência, Diana ética, Diana professora nossa. (Ivan Côrrea)

As características recorrentes que aparecem nesses depoimentos apontam não só ao modo de ser de nossa homenageada, ao seu estilo de ser no mundo - para lembrar de novo Discini — , mas também para a coerência de seu percurso como professora e orientadora. Como professora, constrói-se um ator do enunciado com domínio do conteúdo ensinado, muita didática, organização e clareza em suas exposições, ótima em exemplos de fácil entendimento, simples, objetiva, inspiradora, porque cheia de entusiasmo, e com uma capacidade de síntese impressionante - isso tudo palavras deles! 
v. 10 (esp.)

87-101 mai.

2020

Todas as características mencionadas são percebidas também nos dois manuais de semiótica publicados pela Diana (Teoria do discurso: fundamentos semióticos, publicado em 1988, e Teoria semiótica do texto, de 1990), os quais são, até hoje - juntamente com as publicações do professor Fiorin -, ponto de partida obrigatório para aqueles que iniciam os estudos em semiótica. Nos dois manuais citados, explicitamse, como vai destacar Portela (2008, p. 94) - em sua tese de Doutorado, que apresenta um estudo sobre os manuais brasileiros de semiótica greimasiana -, "o quão bem tecida é a concepção de Barros sobre a Semiótica e seu ensino", com uma motivação teórica forte, que busca a especificidade histórica e conceitual do campo que explora e que, por isso, delimita bem seu destinatário: o sujeito-aprendiz que quer [e deve] conhecer a semiótica proposta por Greimas como uma teoria do texto e não como um meio de aumentar a sua competência de leitura conforme foi assinalado por um dos depoimentos.

A prática didática de Diana é, portanto, pautada por um compromisso com a teoria semiótica, com o contrato firmado, e reiterado com o mestre, como ela mesma assinala em seu artigo "Formação do semioticista: experiência e paixão semióticas", publicado em 2017a na parte I do dossiê de homenagem a Greimas (Estudos Semióticos, vol. 13, n. 2). Isso explica que em seu percurso profissional como docente transpareça também, com grande efeito persuasivo, as paixões do entusiasmo e da convicção por essa vertente dos estudos do texto e do discurso - conforme corroboram todos os depoimentos recolhidos, e inclusive a minha própria fala neste texto.

Como orientadora, esse ator do enunciado se constrói, a partir dos depoimentos, como uma figura afetuosa, humana e acolhedora, sem deixar de lado sua autoridade e firmeza, que garantem a devida segurança e confiança a seus orientandos. Um Destinador, de fato, "o sujeito responsável pela alteração das qualidades do sujeito da ação [...] aquele que determina a competência e os valores do sujeito que age, aquele que, em suma, estabelece as regras do jogo" (BARROS, 2001, p. 18). Exigente, racional, mas paciente e sempre aberta ao diálogo; postura essa que, bem ilustrada principalmente pelo primeiro relato, condiz com o que se espera do bom orientador, segundo palavras retiradas novamente do estudo de Portela (2008, p. 40): 
mesmo tempo que buscará, por exemplo, atenuar disposições patêmico-somáticas como o tédio, a angústia e a ansiedade, e também paixões como o medo (do novo) ou a inveja (dos demais aprendizes), o sujeito didata deverá encontrar formas de despertar e controlar paixões como a curiosidade, a piedade (solidariedade) ou a emulação construtiva. O controle do diapasão passional na situação didática revela-se fundamental para a eficácia da formação a que quer submeter o aprendiz.

Esse conjunto de traços, que se sobrepõe ao percurso profissional da Diana, aqui brevemente exposto, no qual foram enfatizadas, sobretudo, suas atividades docentes, não deixa dúvida quanto ao compromisso e à dedicação - no fundo, à paixão - ao projeto de ensinar, de formar. Trata-se, portanto, de um ator do enunciado que faz do dever ético da profissão um querer apaixonado, dotado de farta competência modal, porque sujeito que sabe e pode-fazer, e o faz com êxito, mantendo em constante diálogo, ao longo de sua performance, o estado de coisas e os estados de alma, ou seja, uma performance de formação do semioticista, na qual dialogam "experiência e paixão semióticas" (BARROS, 2017a).

Para terminar, gostaria ainda de chamar a atenção para mais um aspecto de seu compromisso com o ensino e a divulgação da semiótica.

\section{Contribuições à Educação Básica}

Ainda que tenha feito toda a sua carreira docente no ensino superior, Diana manteve, nesse percurso, um olhar atento também à Educação Básica, à formação escolar, como comprovam algumas de suas publicações. Entre elas estão:

(i) O artigo "Língua, literatura e ensino na perspectiva do discurso", publicado na revista Scripta, em 2004, no qual Diana discorre, a partir do ponto de vista da semiótica discursiva e pensando no ensino de literatura na escola, sobre as intersecções que devem se estabelecer entre os estudos do discurso, a análise e o trabalho com os textos literários em sala de aula. Para isso, ela toma como base quatro aspectos: (1) o da análise narrativa e discursiva do texto literário; (2) o dos problemas do plano da expressão, a partir da noção de semissimbolismo; (3) o dos efeitos estéticos e da percepção estética; e, de maneira mais breve, (4) o das relações entre o texto literário e o contexto. 
v. 10 (esp.)

87-101 mai.

2020

Nesse artigo, seu objetivo principal é o de mostrar a seus leitores a importância, para o tratamento do texto literário na escola, de ter por detrás uma teoria do discurso como a Semiótica, que oferece ao professor amplo instrumental para análise minuciosa do texto literário.

(ii) O capítulo "Língua falada e ensino", publicado no livro Língua Portuguesa e Lusofonia, organizado por Neusa Barbosa Bastos em 2014, trata, também pelo viés da semiótica discursiva, das modalidades falada e escrita da língua portuguesa, passando, na sequência, a discutir o interesse de um estudo dessa natureza para o ensino na Educação Básica. O texto está organizado em quatro partes centrais: num primeiro momento, Diana discute as diferenças entre fala e escrita, em especial, nas posições intermediárias que podem ser encontradas entre o texto falado e o texto escrito; no segundo tópico, procura mostrar o modo como a língua falada é tratada e normatizada nas gramáticas mais antigas do português; em terceiro, ela examina, a partir da caracterização da fala e da escrita ideais, os efeitos de sentido da oralidade nos discursos, os procedimentos que produzem esses efeitos em textos diversos (verbais escritos, visuais, gestuais e outros), bem como o papel desses recursos entre as estratégias de persuasão utilizadas pelo destinador do discurso para manipular seu destinatário; e, por fim, na quarta parte, ela mostra o interesse desse tipo de estudo para o ensino de português na escola, o qual permite ao aluno perceber os modos de exploração, produção e interpretação do sentido também na modalidade oral da língua.

(iii)Outro capítulo escrito por ela é "Intolerância e ensino", publicado, em 2016, em coletânea mais recente da série Língua Portuguesa e Lusofonia, organizada também pela professora Neusa Barbosa Bastos. Esse estudo traz uma discussão sobre a importância do trabalho na escola com textos que exemplifiquem a intolerância e o preconceito na e da linguagem, "para que sejam abertos e percorridos alguns caminhos que levem tanto à aceitação social 
da diferença, quanto à inclusão do diferente" (p. 195). Chamando a atenção para a construção discursiva desse tipo de discurso, Diana apresenta, em continuidade com outros trabalhos desenvolvidos anteriormente, uma proposta teórica e metodológica para depreensão dos procedimentos e estratégias que neles se podem identificar, discorrendo sobre o modo como a questão pode ser tratada em sala de aula, tanto para o combate à intolerância na sociedade, quanto para a transformação de discursos preconceituosos em discursos de aceitação e inclusão social.

(iv) O capítulo de livro "Algumas reflexões sobre a enunciação: o actante e o ator da enunciação nos discursos", publicado no livro Estudos Linguísticos: língua, história, ensino, organizado, em 2017c, pelos professores do Mackenzie Maria Lúcia Marcondes Carvalho Vasconcelos, Ronaldo de Oliveira Batista e Helena Bonito Pereira, discute os procedimentos discursivos utilizados na construção do ator da enunciação, mostrando como isso pode transformar-se também em objeto de ensino.

(v) e, mais recentemente, em 2018, o capítulo "Sentidos e intolerâncias em O navio negreiro", no livro organizado por Ronaldo de Oliveira Batista e Alexandre Huady Torres Guimarães, A poesia na sala de aula: leituras de O navio negreiro, no qual ela explicita a organização narrativa e discursiva do discurso preconceituoso, como atitudes de sanção, que se podem depreender a partir do texto examinado, enfatizando uma vez mais o importante papel da escola na eliminação da intolerância na sociedade.

Para além desses textos, lembro ainda dos dois simpósios organizados pela Diana, em parceria com a professora Lucia Teixeira, da Universidade Federal Fluminense, ambos dedicados ao debate "Semiótica e Educação". O primeiro foi em 2018, no III Congresso Letras em rede, sediado no Mackenzie, que propunha, para o diálogo necessário entre os estudos semióticos do discurso e o ensino, quatro caminhos: (i) o de verificar como a semiótica, enquanto proposta teórica e metodológica, trata das relações entre discurso científico, 


\section{v. 10 (esp.}

87-101 mai. 2020

pedagógico, didático e de divulgação, e, principalmente, das operações de didatização e divulgação; (ii) o de examinar os materiais didáticos como discursos, aí incluindo os livros didáticos, as gramáticas, as coletâneas, os dicionários, os cadernos de alunos, os planos de aula e outros; (iii) o de analisar as formas de divulgação da teoria semiótica e seu papel no ensino e na construção das ideias linguísticas no Brasil; e, por último (iv) o de tratar das relações entre as novas tecnologias e o ensino. Foi um simpósio bastante produtivo, composto por dezessete apresentações que contemplavam esses tópicos.

O segundo simpósio foi "Discurso e educação: balanço dos estudos do discurso desenvolvidos em diferentes perspectivas teóricas", realizado em agosto de 2019, no VII Simpósio Mundial de Estudos de Língua Portuguesa (SIMELP), no qual o debate é ampliado, abrindo ainda mais dois caminhos possíveis para a discussão: (i) mostrar a importância da escola na construção dos discursos de aceitação e inclusão sociais; e (ii) investigar a fundamentação, objetivos e propostas de documentos oficiais, como a Base Nacional Comum Curricular (BNCC) e as diretrizes estaduais e municipais de ensino, particularmente em relação às disciplinas de língua portuguesa, línguas estrangeiras e literatura. Neste, foram dezesseis as apresentações dedicadas ao tema.

Enfim, do ensino superior ao ensino básico, vemos Diana Luz Pessoa de Barros sempre atenta a dar a sua melhor contribuição como professora e pesquisadora, buscando a formação sólida de seus alunos, científica e cidadã, permanentemente aliando rigor e afeto. Essa é a Diana professora, orientadora. Essa é a prática apaixonada de uma semioticista exemplar.

\section{Referências}

BARROS, D. L. P. de. Teoria semiótica do texto. São Paulo: Editora Ática, 1990.

BARROS, D. L. P. de. Teoria do discurso. Fundamentos semióticos. São Paulo: Humanitas, 2001 [1988].

BARROS, D. L. P. de. Língua, literatura e ensino na perspectiva do discurso. Scripta, v. 7, n. 14. Belo Horizonte (PUC-MG), 2004. p. 33-40.

BARROS, D. L. P. de. Língua falada e ensino. In: BASTOS, N. B. (org.). Língua Portuguesa e Lusofonia. São Paulo: EDUC, PUC-SP, 2014. p. 151-168.

BARROS, D. L. P. de. Intolerância e ensino. In: BASTOS, N. B. (org.). Língua portuguesa e lusofonia: história, cultura e sociedade. São Paulo: EDUC, PUC, 2016. p. 195-210. 
BARROS, D. L. P. de. A formação do semioticista: experiência e paixão semióticas. Estudos Semióticos, vol. 13, n. 2. São Paulo, 2017a. Disponível em: https://www.revistas.usp.br/esse/article/view/141598/136608

BARROS, D. L. P. de. Texto de Diana Luz Pessoa de Barros aprsentado no evento "O percurso da Semiótica na USP: uma homenagem a Diana Luz Pessoa de Barros, José Luiz Fiorin, Beth Brait, Luiz Tatit e Norma Discini". Auditório István Jancsó da Biblioteca Brasiliana Guita e José Mindlin, USP, São Paulo. 05 de maio de 2017b. Disponível em: http://semiotica.fflch.usp.br/sites/ semiotica.fflch.usp.br/files/u57/Hommage_Diana\%20Luz\%20Pessoa\%20 de\%20Barros.pdf

BARROS, D. L. P. de. Algumas reflexões sobre a enunciação: o actante e o ator da enunciação nos discursos. In: VASCONCELOS, M. L. M. C.; BATISTA, R. de O.; PEREIRA, H. B. (org.). Estudos Linguísticos: língua, história, ensino. São Paulo: Editora Mackenzie, 2017c. p. 115-127.

BARROS, D. L. P. de. Sentidos e intolerâncias em O navio negreiro. In: BATISTA, R. de O.; GUIMARÃES, A. H. T. (org.). A poesia na sala de aula: leituras de $O$ navio negreiro. São Paulo: Editora Mackenzie, 2018. p. 259-290.

DISCINI, N. O estilo e o ator da enunciação: Greimas na contemporaneidade. Estudos Semióticos, vol. 14, n. 1. São Paulo, 2018. p. 117-132. Disponível em: https://www.revistas.usp.br/esse/article/view/144315/138714

PORTELA, Jean Cristtus. Práticas didáticas: um estudo sobre os manuais brasileiros de semiótica greimasiana. Tese de Doutorado. Universidade Estadual Paulista "Júlio de Mesquita Filho", UNESP, Araraquara, 2008.

RALLO-DITCHE, E.; FONTANILLE, J.; LOMBARDO, P. Dictionnaire des passions littéraires. Paris: Belin, 2005.

THÜRLEMANN, F. L'admiration dans l'esthétique du XVIIe siècle. Actes Sémiotiques. Documents, II, nº 11, Paris, CNRS, 1980. 